\title{
Database Design on Classification Detailed Account for Educational Materials
}

\author{
Gexin Chang ${ }^{1, a}$, Wenfeng Song ${ }^{2, b}$ \\ ${ }^{1}$ College of Information Science and Technology, Bohai University, Jinzhou, 121013, China \\ ${ }^{2}$ State Grid Dalian Electric Power Supply Company, Dalian, 116001, China \\ a45438443@qq.com, b13909863238@139.com
}

Keywords: educational materials; classification detailed account; conceptual structure design; logical structure design; physical structure design

\begin{abstract}
Educational Materials management is a complicated system engineering, detailed account management is an indispensable part. According to the deficiencies of the manual detailed account management, the database design of detailed account. First, using the E-R model study conceptual structure design; second, study logical structure design, clarify general principle of the concept model transforms the relation model, study table design of "material detailed ledger head" and "detail of material detailed ledger"; third, study physical structure design, including disk hardware selection, data storage on the disk, create index for improving access performance. This paper is about the fundamental work of educational materials informational construction, it is important reference value for other detailed accounts management too.
\end{abstract}

\section{Introduction}

Material management shows enterprise in the process of production, organization, control and plan of enterprise behavior of materials purchasing, using, reserving and so on [1]. Many large enterprises usually need thousands kinds of materials and even ten thousand kinds of them. Materials department is responsible for enterprise of all materials purchase, storage and delivery. Materials department including plan to purchase, storage management, audit statistics etc, According to their respective functions, these departments manage enterprise materials together, so all sorts of goods and materials for production and operation remove in a timely and effective manner [2,3]. In the traditional manual management, thousand kinds of materials writes by several warehouse keepers in several material detailed ledger, the weakness of it is: the slow speed of queries and getting, the slow speed of information transfer, could not share, easy to cause the mistake, repeated labor, repeat reserves, overstocked products, could not know the material status, etc. To solve these weaknesses, the best method is to use computer to realize the detailed account management. A material corresponds to one account, when a new materials put in storage, the system automatically adds a page, not inventory last year, first record is incoming data and inventory data, incoming data and inventory data are equal; when goods out, according to material requisition write a record into system, abstract indicates the unit, record documents number, spending data, and calculates the inventory data. Database design is a technology for establishing a database and its application system, it is important for software design. To be specific, database design is in a given application environment, structure optimal database model, establishment of database and its application system that will be able to effectively stored data to meet all kinds of user's application requirements. This paper conduct material classification detailed account to conceptual structure design, logical structure design, physical structure design. It is basic work to construct material management system. 


\section{Conceptual Structure Design}

Concept structure design task is in demand analysis stage and the cause of the requirements specifications, and on the basis of the specific method according to the abstract for a does not rely on any specific machine data model, that is a concept data model. Concept model to the attention of the designer data from complex implementation details can be freed, but only focused on the most important information, organization structure and processing model. The conceptual model, mainly in the system development database design stage use, according to the user's point of view is to data and information modeling, use entity relationship chart to achieve. Concept model describes the system of each entity and related entities, the relationship between the system and static characteristics is described. E-R chart also called Entity Relationship Diagram, provides said the type of entity, properties, and contact method, used to describe the concept of real world model [4].

E-R method is the "entity-relationship Approach" abbreviation, is to describe the real world concept the model of the structure of effective method, is said to the conceptual model of a way. With rectangular said entity type, rectangular box of entity within the name; The attributes of the entity with elliptic said, and to the movie and without the corresponding with the entity type connected; With the diamond said the link between type entities, in the box in the diamond of contact name, and no to the edge of the related entities are connected, and at the same time to the side in the absence of contact on mark type (1:1, 1 : $n$ or $\mathrm{m}: \mathrm{n})$.

In the material detailed account, account for a head the basic information of the materials, detail stored put into detailed information, the relation is one to many, the relation between the E-R chart shown in Fig. 1.

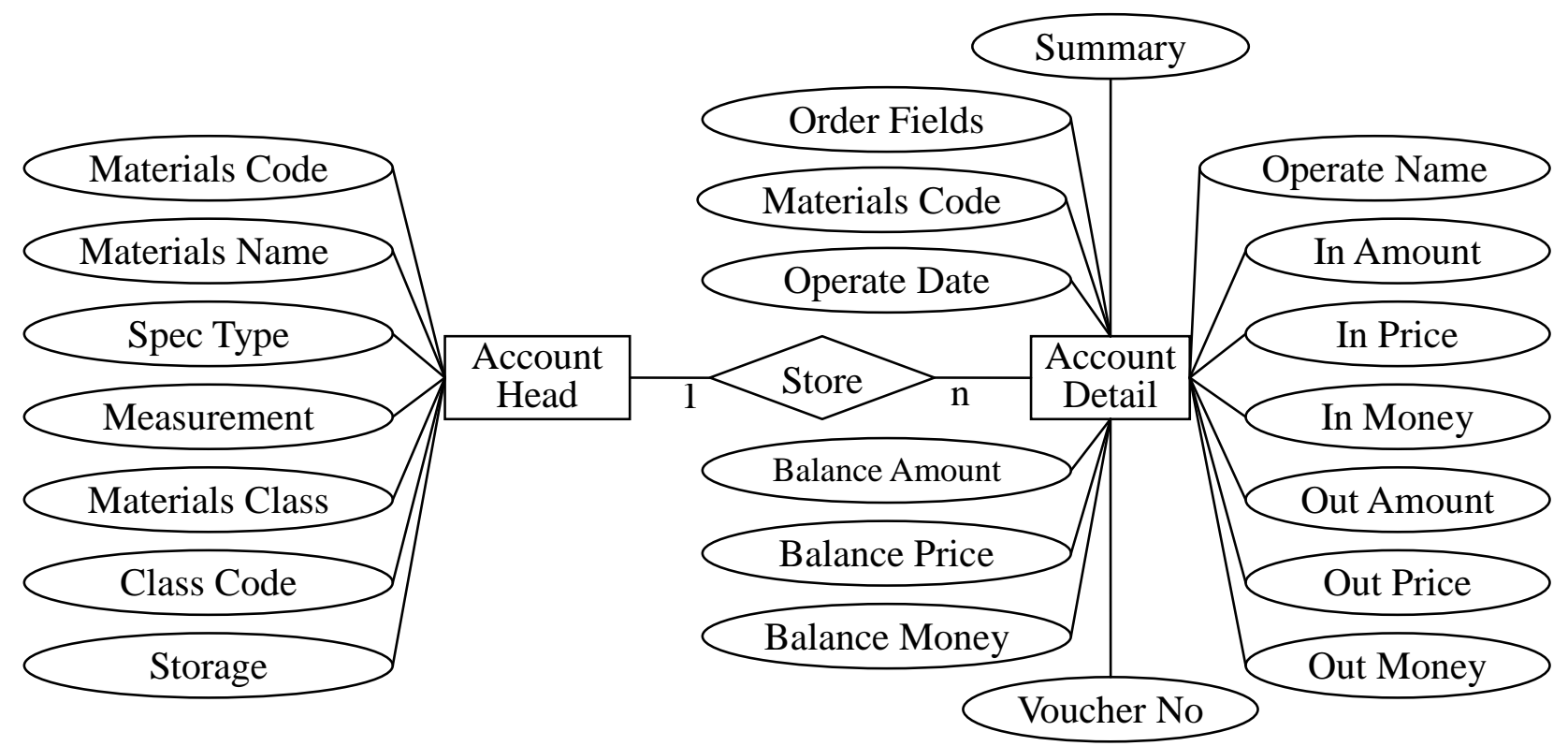

Fig. 1. E-R Diagram of Materials Classification Detailed Account

\section{Logical Structure Design}

Logic structure design task is to put the concept structure design of the e-r chart, and is converted to the database management system product support data model fit with the logical structure. Relation model and relational database management system has been generally accepted and widely used. This paper chooses Microsoft SQL Server is relational database management system. Relation model of logic structure is a group of relationship model set, e-r chart into relation model is the entity, the entity attributes and entities of the relationship between conversion for relationship model, generally follow the following principles [5]:

(1) An entity type transfer into a relationship model. The attributes of the relationship is the 
entity attribute, the code is entity relationship code.

(2) A 1: n contact can be converted to an independent relationship model, and can also $n$ the corresponding relationship with the model. If converted to an independent relationship model, is connected with the contact of the entities and contact the attributes of the code itself are converted to the attributes of the relationship, and the relationship of the entity code for $n$ code.

\section{Materials Classification Detailed Account Head}

A material code has a record, structure is shown in Table 1.

Table 1. Materials Classification Detailed Account Head (Table name: Ope_Account_Head)

\begin{tabular}{|c|c|c|c|}
\hline No & Fields Name & Type & Width \\
\hline 1 & Primary_Key & varchar & 22 \\
\hline 2 & Materials_Code & varchar & 10 \\
\hline 3 & Materials_Name & varchar & 50 \\
\hline 4 & Spec_Type & varchar & 50 \\
\hline 5 & Materials_Unit & varchar & 20 \\
\hline 6 & Materials_Class & varchar & 20 \\
\hline 7 & Class_Code & varchar & 2 \\
\hline 8 & Storage & varchar & 50 \\
\hline 9 & Balance_Amount & decimal & 13,2 \\
\hline 10 & Balance_Price & decimal & 13,2 \\
\hline 11 & Balance_Money & decimal & 13,2 \\
\hline
\end{tabular}

\section{Materials Classification Detailed Account Head Detail}

The table can't modify delete operation, if you want to really need to modify delete operation, the negative warehouse or negative outbound to achieve. A material code has a record, structure as shown in Table 2.

Table 2. Materials Classification Detailed Account Detail (Table name: Ope_Account_Detail)

\begin{tabular}{c|l|l|c}
\hline No & Fields Name & Type & Width \\
0 & Primary_Key & varchar & 20 \\
\hdashline 1 & Orderby Fields & varchar & 20 \\
\hdashline 3 & Materials_Code & varchar & 10 \\
\hdashline 4 & Operate_Date & varchar & 10 \\
\hdashline 5 & Summary & varchar & 50 \\
\hdashline 6 & Voucher_No & varchar & 10 \\
\hdashline 7 & Operate_Name & varchar & 20 \\
\hdashline 11 & In_Amount & decimal & 13,2 \\
\hdashline 12 & In_Price & decimal & 13,2 \\
\hdashline 13 & In_Money & decimal & 13,2 \\
\hdashline 14 & Out_Amount & decimal & 13,2 \\
\hdashline 15 & Out_Price & decimal & 13,2 \\
\hdashline 16 & Out_Money & decimal & 13,2 \\
\hline$\cdots \cdots n . .$.
\end{tabular}




\begin{tabular}{c|l|l|c}
\hline 17 & Balance_Amount & decimal & 13,2 \\
\hline 18 & Balance_Price & decimal & 13,2 \\
\hline 19 & Balance_Money & decimal & 13,2 \\
\hline
\end{tabular}

\section{Physical Structure Design}

Physical structure design is in logic structure design, and on the basis of choice for each relationship model appropriate storage structure and access method, and makes the affairs of the database to high efficiency operation. Physical structure design depend on specific DBMS, this paper choose Microsoft SQL Server design as follows

\section{Disk Hardware Selection}

Hard drive the performance parameters of many, for access database of hard drive capacity, the choice, mainly from the aspects such as speed, the cache to consider. Material management system data is more, need to choose special database server, want to consider the RAID equipment [9]. RAID by multiple disk drive is composed of disk system, which can provide higher performance, reliability, storage capacity and lower cost. Fault tolerant array into from 0 to five of six RAID levels. Each level use different algorithm to realize fault tolerance. Although RAID not Microsoft ${ }^{\circledR}$ SQL Server TM 2000 part, but its realization directly influences the SQL Server performance. SQL Server use commonly RAID level 0, 1 and 5.

\section{Data Storage On the Disk}

Material management system large amount of data, in order to improve the efficiency of the visit, to create the file group, will be stored in the database tables in the different file group document. If the file group by in the different physical disk carried more files composition, and each disk has its own disk controller, the data in the table in the disk of inquires into, so as to improve the query performance.

If table file group include more than files, may to the single table executes more parallel scanning. Whenever the orderly access to table, create separate thread in parallel read each file. For example, by four documents to the group of files created in table completely scanning, will use four separate thread parallel reading of the data. Duing to use of separate thread parallel scanning each files, so in each file group to create more documents helps to improve performance. Also, when inquires on different connection file group on the table, you can parallel read each table to improve query performance.

\section{Create Index For Improving Access Performance}

The purpose of the index is to speed up the table records of search or order. Generally speaking, should be in these are listed on the create index: in often need to search list, can speed up the search speed; In as the main key columns, forced the list of uniqueness and organization of the data in the table are structure; In connection with the often list, these are listed mainly some foreign key, can accelerate the speed of the connection; According to the range in often need to search are listed on the create index, because the index has been sorting, its designated range is continuous; In the often need to sort are listed on the create index, because the index has been sorting, such inquires the sort can use index, speed up the sort query time; In the often use WHERE clause in the listed above create index, speed up the conditions of the judge speed [10].

In "material subsidiary ledger head" table, press "Lord key word" create the cluster index, click "material code" create the only index, click "category code, material name, specification, measurement unit" create combination index, click "stack position" create the cluster index. In "material subsidiary ledger detail" table, press "Lord key word" create the cluster index, click "sort field" to create the cluster index; Press the "material code, operation date, vouchers order, measurement unit" create combination index. 


\section{Trigger Design}

Trigger is a special kind of storage process, can't be explicitly called, but to insert record in table record update or delete records, was automatically activated. So trigger can be used to realize the integrity of the implementation of table complex constraints [11]. In the material classification subsidiary ledger, design the following three triggers:

At the same time delete data trigger. When "material classification subsidiary ledger head" a record in a table is deleted, account list and delete more records.

And modify data trigger. When "material classification subsidiary ledger head", the table "material code" change, detailed account the corresponding materials coding "also do the same changes.

Insert the inventory according to trigger. When "material classification subsidiary ledger detail" insert data in the table, the number of inventory will certainly change, will inventory quantity wrote bill head table.

\section{Conclusion}

Subsidiary ledger books also called subsidiary ledger, hereinafter referred to as subsidiary ledger, is according to level 2 accountant course or subsidiary open account paper, registration details of one kind of economic business books, subsidiary ledger books is the enterprise according to the unit of the operation and management of the enterprise unit set up independently. Generally speaking, the enterprise unit to all sorts of assets, expenses cost and income results, the creditor's rights debt, money exchanges, should be in the general ledger subjects set up under the subsidiary ledger, subsidiary ledger accounting. Material management is complicated system engineering, in the enterprise management have an important position and role, subsidiary ledger management is indispensable part of [12]. In this paper, the classification of the material subsidiary ledger database design, to other subsidiary ledger's information construction to have the important reference value.

\section{References}

[1] Y. N. Zheng, "On Materials Management of Enterprises," Value Engineering, vol. 31, no. 10, pp. 130.

[2] Mahdi Safa, Arash Shahi, et al, "Supplier selection process in an integrated construction materials management model," Automation in Construction, vol. 48, no. 1, pp. 64-73.

[3] Katsuhiko Kokubu, Hirotsugu Kitada, "Material flow cost accounting and existing management perspectives," Journal of Cleaner Production, vol. 27, no. 8, pp. 126-167.

[4] Baidu Encyclopedia, "Conceptual structure design," http://baike.baidu.com/view/1638403.htm, 2015-7-15.

[5] S. Wang, S. X . Sa, "Introduction to database system (Fourth Edition)," Higher Education Press, 2006.

[6] L. Wang, "Account page (Multi column ledger, Auxiliary A4)," China: CN301438952S, 2011-1-12.

[7] L. Wang, "Account page (Multi column ledger, Lord A4)," China: CN301438954S, 2011-1-12.

[8] Y. H. Yu, "Set multicolumn subsidiary ledge simplified profit distribution accounting," Commercial Accounting, vol. 32, no. 19, pp. 24-25.

[9] Y. C. Ren, T. Xing, X. E, "Software Development Process Management," Beijing Jiaotong University Press, 2010.

[10] Baidu Encyclopedia, "Database index," http://baike.baidu.com/view/2079871.htm, 2015-7-15. 
[11] http://baike.baidu.com/link?url=YJDMSxGtp8bQD2hFAxgjan0Tfvdz9YUJcWWmYsQJ9-g4b 2XpQ4KIUbaIpCHTYyjVwSZQYPY2qpYA5pZmHsPd2ui9VN3Pvy, 2015-7-15.

[12] C. S. Yang, "The material management work key point and effect," Modern Economic Information, vol. 26, no. 24, pp. 41. 